\title{
Seed-Biopriming of Durum Wheat with Diazotrophic Plant Browth Promoting Bacteria (PGPB) Enhanced Tolerance to Fusarium Head Blight (FHB) and Salinity Stress
}

\section{Adel Hadj Brahim}

Centre de Biotechnologie de Sfax

Mouna Jlidi

Centre de Biotechnologie de Sfax

\section{Lobna Daoud}

Centre de Biotechnologie de Sfax

Manel Ben-Ali

Centre de Biotechnologie de Sfax

Asmahen Akremi

Centre de Biotechnologie de Sfax

\section{Houda Hmani}

Centre de Biotechnologie de Sfax

Naser Aliye Feto ( $\square$ anaser22@yahoo.com )

Vaal University of Technology https://orcid.org/0000-0002-6781-6683

Mamdouh Ben-Ali

Centre de Biotechnologie de Sfax

\section{Research article}

Keywords: Diazotrophic; Bacillus, Seed Biopriming, Bioprotection, Fusarium Head Blight, Abiotic Stress, Salt Tolerance, Durum Wheat

Posted Date: October 31st, 2019

DOI: https://doi.org/10.21203/rs.2.16636/v1

License: (c) (1) This work is licensed under a Creative Commons Attribution 4.0 International License. Read Full License 


\section{Abstract}

Background The use of bioinoculants based on plant growth-promoting bacteria (PGPB) to promote plant growth under biotic and abiotic stresses is in full expansion. To our knowledge much work has not been, thus far, done on seed-biopriming of durum wheat for tolerance to biotic and abiotic stresses. In the present work, we report detailed account of the effectiveness a potent bacterial strain with proven plant growthpromoting ability and antimicrobial activity. The isolate was selected following screening of several bacterial strains isolated from halophytes that grow in a coastal saline soil in Tunisia for their role in enhancing durum wheat tolerance to both salinity stress and head blight disease.

Results Accordingly, Bacillus strains MA9, MA14, MA17 and MA19 were found to have PGPB characteristics as they produced indole-3-acetic acid, siderophores and lytic enzymes, fixed free atmospheric nitrogen, and solubilized inorganic phosphate, in vitro. The in vivo study that involved in planta inoculation assays under control $(25 \mathrm{mM} \mathrm{NaCl})$ and stress $(125 \mathrm{mM} \mathrm{NaCl})$ conditions indicated that all PGPB strains significantly ( $P$ $<0.05$ ) increased the total plant length, dry weight, root area, seed weight, nitrogen, protein and total mineral content. On the other hand, strain MA17 reduced Fusarium Head Blight (FHB) disease incidence in wheat explants by $64.5 \%$, showing that the strain has antifungal activity as was also displayed by in vitro inhibition study.

Conclusions Both in vitro and in vivo studies showed that MA9, MA14 MA9, MA14, MA17 and MA19 strains were able to play the PGPB role. Yet, biopriming with Bacillus strain MA17 offered the highest bioprotection against FHB, plant growth promotion, and salinity tolerance. Hence, the MA17 strain should further be evaluated under field condition and formulated for commercial production. Besides, the strain could further be evaluated for its potential role in bioprotection and growth promotion of other crop plants. We believe, the strain has potential to significantly contribute to wheat production in the arid and semi-arid region, especially the salt affected Middle Eastern Region, besides its potential role in improving wheat production under biotic and abiotic stresses in other parts of the world.

\section{Background}

Biotic and abiotic stresses have been reported to severely limit crop growth and yield [1]. Salinity is one of the most important abiotic stress factors affecting crop production. Several studies predicted that climate change would increase risk of salinization at different latitudes. In Tunisia, salt-affected areas are fast escalating due to intrusion of saline water into arable lands and the use of chemical fertilizers and pesticides (Fig. S1).

To reduce the toxic effects of salt $(\mathrm{NaCl})$ stress on plants, different tools have been developed such as plant genetic engineering [2], and the use of plant growth-promoting bacteria (PGPB) [3].

PGPB are known to be able to grow in, on, or around plant tissues, and to elicitate their growth of plants by different manners [4]. These PGPB strains can be used in different ways to improve crop productivity. The first way as simple inoculation that might be carried out with a pure or with a combination of two or more 
strains either belonging to the same [5] or to different genotypes [6]. The second way as seed biopriming before the germination phase [7].

Priming methods are used to enhance seed germination either under optimal or stress conditions [8]. Interestingly, the positive impact of priming was found to be more pronouced under stress than normal conditions [9]. Among the valuable physiological approaches, seed priming, as an easy, low cost and low risk technique, can allow to a glycophyte species to grow under saline conditions [10-12].

This technique was successfully used in many crops including hot pepper [13, 14], lettuce [15], maize [16], okra [17], tomato [18], pea [19], pepper[20], milk thistle [21] and soybean [22]. The applicationof PGPB strains via seed biopriming through soaking grains during a specified period of time in a liquid suspensioninitiated the seed germination functional processing, but during this process, radicle and plumule were not allowed to emerge [23]. Biopriming intended to improve tolerance to salinity and $d$ efficient protocols have been established. The most used genus is Bacillus and this the case with various crops from potato [24], radish [25], rice, mung bean and chickpea [26].

The halophytes are able to grow under salt stress through different physiological and biochemical mechanisms besides to their interactions with the associated PGPB. , However, there are no published works on the mechanisms behind the effect of the endophytic or rhizospheric bacteria associated to thesehalophytes in natural saline conditions.

Hence, the main purposes of our present research were: (1) the isolation and identification of the strains with PGPB traits, (2) the evaluation of the biocontrol effect of these strains against Fusarium attack in durum wheat, and (3). the study of the effect of PGPB on promoting plant growth under salt stress.

\section{Results}

Biochemical characterization of PGPB strains Our strains (MA9, MA14 MA9, MA14, MA17 and MA19) were found to be able to metabolise sucrose, mannitol, glucose, starch, citrate, and nitrate. When the isolates tested for their tolerance to different temperature degrees and salinity concentrations and various $\mathrm{pH}$ levels, we found that almost all of them were able to grow under $\mathrm{NaCl}$ concentrations ranging from 0 to $7 \%$, with optimal growth at of $30 \mathrm{oC}$ and pH 6.5 (Fig. S2). In addition, all selected strains were positive for $\beta$ glucanase, protease, chitinase as well as for important plant growth promoting (PGP) properties including production of siderophores (Fig. 1), exopolysaccharides, antimicrobial compounds and hydrolytic potential of 1-aminocyclopropane-1-carboxylate (ACC deaminase + ) (Table 1). The majority of the tested strains were found to produce variable amounts of auxins (Fig. 2) ranging from 35 to $376 \mu \mathrm{g} / \mathrm{mL}$ except for MA17 and MA19, which produced relatively less auxin with and without tryptophan: 56/109 and 35/125 $\mu \mathrm{g} / \mathrm{mL}$, respectively. Particularly, MA14 was found to produce indole acetic acid (IAA) more than other tested strains and showed a higher yield than values previously reported in literature [27]. The isolates also showed phosphate-solubilizing activity as evidenced by the formation of clear zones on NBRIP agar plates. In the liquid NBRIP medium, bacterial strains solubilized variable amounts of phosphates ranging from 78 to 476 $\mu \mathrm{g} / \mathrm{ml}$ (Fig. 2). Antifungal activity for the different isolates was evidenced by the formation of inhibition zones between the bacterial isolates and the fungal isolates (Table 1). Among which, MA17 showed the 
highest antifungal activities against F. oxysporum (Table 1). All of the tested diazotrophic bacteria, except MA14, showed antagonistic effects to both R. solani, and F. graminarum. Molecular profiling of the PGPB starins The analysis of the 16S rRNA gene-based sequences for the different PGPB strains was done using BLASTn of the sequences against the NCBI's database. We found that the sequences of isolates MA9 and MA17 showed 99\% similarity with Bacillus pumilus Bp02 (DQ910855.2), and Bacillus pumilus ML270 (KC692158.1), respectively,hile, the isolate MA19 showed 98\% similarity with Bacillus tequilensis BPR061 (KU161291.1) and MA14 showed 84\% similarity with Virgibacillus sp. SKW19 (KU132375.1). Diazotrophic potential of the isolates The results in Table 2 confirmed the diazotrophic activity of these PGPB strains. Almost of the tested strains were able to grow in the mineral medium without any nitrogen source and added with 1-Aminocyclopropane-1-carboxylate (ACC), the only available nitrogen source, and with glucose as the unique carbon and energy source (Table 2; Fig. S2). MA14 and MA17 strains were the most efficient ones in terms of biofilm formation after growing in a NFMM medium without nitrogen source, but MA14 exhibited the lowest capacity of acetylene reduction. Both strains (MA14 and MA17) were also found to produce ethylene after $72 \mathrm{~h}$ of incubation (data not shown) based on the acetylene reduction test and the CPG analysis of gases in the head spaces. These satrins were shonw to have nitrogenase activities ranging from 0.452 to $3.125 \mu \mathrm{mol} \mathrm{C} 2 \mathrm{H} 4 \mathrm{mg}$ protein/h based on the acetylene reduction assay (ARA) . In addition, MA17 isolate showed maximum ARA and Kjeldhal levels of nitrogen but this strain had the fewest potential of growth on an $\mathrm{N}$-free medium. The ARA test was verified by measuring $\mathrm{N} 2$ by the Kjeldhal method of bacterial culture in NFMM medium. These results suggest that these strains had active nitrogenase. The growth test revealed that the three strains MA9, MA14 and MA17 grew very well in the medium ACC between nitrogen free mineral medium, releazing N2 gas in the head space. Meanwhile, MA19 grew equally on NFMM and NFMM+ACC (Fig. S2). Evaluation of mechanisms regulating plant homeostasis ACC deaminase activity assays in vitro in a chemically defined medium were carried out to check wether the different strains might play a role in regulating plant stress homeostasis . In fact, bacterial culture in NFMM medium with 5 $\mu \mathrm{g} / \mathrm{mL}$ of 1-aminocyclopropane-1-carboxylate (ACC) suggested active metabolic pathways of ACC degradation for these four PGPB strains (Figure. 3). Almost of bacterial strains were able to grow based on ACC deaminase activity. As known, the ACC metabolic pathway might promote plant growth under stress conditionsby reducing the ethylene concentration in plant cells. In this context, numerous PGPB strains that are able to produce AcdS were found to ameliorate plant growth under various stress factors [28, 29]. Biocontrol effect of PGPB strains against pathogen F. graminarum in wheat Biocontrol experements were conducted to evaluate the protective effect of two selected PGPB strains (MA17 and MA14) against Fusarium graminarum in wheat. The data obtained revealed that head blight severity was reduced in samples inoculated by these strains compared to the untreated control plants. MA17 strain was more efficient than MA14 in terms of wheat protection from the pathogen infection. MA14 did not exhibit an in vitro antifungal activity against $F$. graminarum which means that indirect mechanisms might be involved (induced systemic resistance, ISR) or nich exclusion in its in vivo activity. In fact, this might be due to specific biological activities like the production of siderophores, lytic enzymes or growth hormones. MA17 strain provided a more efficient fungal resistance in the soil without fertilizer compared to MA14 (the disease index was 76 and $36 \%$ for, respectively, MA14 and MA17). In fact, the biocontrol efficiency was 64.5 and $24.5 \%$ when soil inoculated with MA17 and MA14, respectively (Table 3). Moreover, MA17 was found to offer both wheat plant growth promotion and an enhanced resistance to head blight (Table 4, 5). The 
biocontrol efficiency was also refletcted by an enhancement of explant morphological parameters such as root length, shoot length, total length, total dry weight, total survival plants after treatment, and disease index. Overall, seed biopriming with both MA14 and MA17 provided a significant resistance to head blight in wheat explants, nevetheless, MA17 was more efficient than MA14 in terms of disease reduction efficiency (Fig.S3 - S8). Effect of seed bacterization by PGPB on wheat growth under salt stress PGPB seed bacterization enhanced germination rate Tolerance capacity of selected PGPB strains to different salt concentrations was measured after seven days of culture. The results indicated that both MA17 and MA19 are two halotolerant strains as they showed greater tolerance capacities compared to both MA9 and MA14. In order to determine the effective salt concentration on limiting wheat plant growth to be used in the entire experiments, the sensitivity of durum wheat $\mathrm{cv}$. Aouija was assessed at different $\mathrm{NaCl}$ concentrations. Accordingly, plant growth was affected at $50 \mathrm{mM} \mathrm{NaCl}$ and severely retarded at $120 \mathrm{mM} \mathrm{NaCl}$. Thus, the latest concentration was chosen for the further assays. Regarding germination assays, we found that all PGPB strains enhanced wheat seed germination under salt stress compared with the negative control (120 $\mathrm{mM} \mathrm{NaCl}$ ) (Fig. 4). MA9, MA14, MA17 and MA19 significantly improved the germination rate by 47, 50, 57 and $40 \%$ under $120 \mathrm{mM} \mathrm{NaCl}$ treatment, respectively. Also, under normal conditions (positive control), almost of PGPB strains significantly improved the germination rate of wheat seeds (Fig. 4). Biomass promotion of wheat plants by PGPB seed biopriming The treatment of durum wheat seeds with halotolerant strains significantly improved root length under stress $(125 \mathrm{mM} \mathrm{NaCl})$ as well as under normal growing conditions except of MA19 strain, which reduced root length by $71 \%$ in the absence of stress. The growth improvement rates were 40,131 and 70 for MA9 MA14 and MA17, respectively, in stress-free culture and 48, 459, 27 and 70\%, respectively, for MA9, MA14, MA17, and MA19 in stress culture. However, the plant biomass was markedly increased after seed biopriming with MA17 and MA19 strains. The latter showed a significant plant development under 25 and $120 \mathrm{mM}$, as opposed to biopriming by MA9 and MA14 whose biopriming improved the length of the roots. However, it had no remarkable effect on the plant biomass which was reduced by $10 \%$ with MA9 in normal culture and by $7 \%$ with MA14 under stress conditions. The development of root length can be explained by an aggressive nutrient deficiency of the plant after inoculation by these two strains which have an inefficient biological activity spectrum under stress. The highest effect on growth under stress was observed in MA14 strain (459\%) in the length of roots and MA17 in the vegetable mass (98.94\%) (Table 4) (See Fig. S9). Biopriming seed with these four diazotrophic strains increased the dry weight of durum wheat var "Aouija". This induction effect was more pronounced under salinity conditions than under control conditions (Table 5) (See Fig.S10). In fact, the percentage of improvement, respectively under stress and non-stress, for MA9, MA14, MA17 and MA19 was 145, 51; 162, 82; 637, 200 and 166,114, while the mass of 100 grains was more important in stress conditions than in under normal conditions for all the strains tested except of MA19. The highest plant growth promotion percentage was observed in MA17 bioprimed seeds under stress with a plant dry weight and a 100-seed mass of 63.7 and 77\%, respectively (See Fig.S12). In addition, seed bacterization with MA14, MA17 and MA19 strains induced an increase in root length by $48,45.9,27$, and $70 \%$, respectively, and in shoot length by $15,7,99$ and $39 \%$, respectively as compared to controls (untreated seeds) subjected to $\mathrm{NaCl}$. However, treatment with MA19 decreased root length by $71 \%$ and enhanced shoot length by $48 \%$ in comparison with the controls (untreated seeds). In contrast, the strain MA14, displayed no significant impact on wheat plant growth parameters under non-saline conditions. Seed biopriming with PGPB strains, except of MA9, offered 
greater enhancement growth in comparison to control plants, whereas under natural and saline treatments, they showed a promotion in shoot length and in total dry weight parameters (Table 5, 6). In fact, plant dry weight was increased at 25 and $120 \mathrm{mM} \mathrm{NaCl}$ for all the PGPB strains. However, at $120 \mathrm{mM} \mathrm{NaCl}$, except of MA14, inoculated plants showed significant increase in root length. At $25 \mathrm{mM} \mathrm{NaCl}$, the root length of inoculated plants with MA17 was markedly increased compared to uninoculated and other PGPB-inoculated plants (See all Fig. S9 - S13). These results indicated and the usefulness of MA19 to enhance wheat plant growth under salt stress. Effect of PGPB treatments on $\mathrm{N}$ and protein contents in wheat seeds The $\mathrm{N}$ and protein contents in wheat seeds in response to PGPB isolates under both stress and control conditions are shown in Figure 5. Both $\mathrm{N}$ and protein contents in wheat seeds were affected (P 0.05) in response to stress treatments. In fact, the total nitrogen content in untreated seeds was 1.06 and $1.71 \mathrm{~g} .100 \mathrm{~g}-1$, while, it ranged from 1.796 to $1.93 \mathrm{~g} .100 \mathrm{~g}-1$ and from 1.799 to $1.85 \mathrm{~g} .100 \mathrm{~g}-1$ for bioprimed plants under stress and natural conditions, respectively. Among the different amendments, seed biopriming with the different isolates before germination provided an enhancement of these parameters compared to both untreated seeds under stress and natural conditions. The highest total $\mathrm{N}$ content of $1.93 \mathrm{~g} .100 \mathrm{~g}-1$ was recorded in plants bioprimed with MA17 under stressful conditions (125 mM NaCl) followed those with MA19, MA14 and MA9 with 1.826, 1.807 and $1.796 \mathrm{~g} .100 \mathrm{~g}-1$ with , respectively. The comparative upsurge in total nitorgen content in plants bioprimed with MA9, MA19, MA14 and MA17 compared to the negative control (salinized soil) was 69, 72, 70 and $82 \%$, respectively, and $4.6,8.2,7$ and $8.2 \%$, respectively compared to the control (soil without $\mathrm{NaCl}$ ). A such increase in $\mathrm{N}$ content by PGPB relied on by their capacity to colonize the soil colonization and to grow stress environments. Nitroginase activity was recorded in all PGPB traetemnts (Table2), indicating the interplay between nitogen and protein contents in plant and N2 fixation (Figure 5). Application of different PGPBs under stressful condition significantly (P 0.05) increased plant protein contents in the range of 10.25 and $11.07 \mathrm{~g} .100 \mathrm{~g}-1$ literally doubling the content as compared to the non-treated control. The highest protein content of $11.07 \mathrm{~g} .100 \mathrm{~g}-1$ was recorded for MA17 under salt stress followed by that for for MA17 under normal conditions (10.61 g.100 g-1 ). In the controls (without biopriming and without $\mathrm{NaCl}$ ), the total protein content was $10.02 \mathrm{~g} .100 \mathrm{~g}-1$. Moreover, there was a relative increase in protein content in plants treated with PGPB strains MA9, MA14, MA17 and MA19 compared to the control by 2.29, 3.4, 10.47 and 3.6 $\%$, respectively. Seed biopriming enhanced the total mineral content The total mineral content in positive control plants (-PGPB, - $\mathrm{NaCl}$ ) decreased by $72 \%$ compated to that subjected to $\mathrm{NaCl}$ treatment. In addition, a reduction by $40 \%$ in dry weight was noted in negative control plants ( $\mathrm{NaCl},-\mathrm{PGPB})$ when compared to controls (Fig. 6). The plants inoculated with selected PGPB showed an increase in their total mineral content either in the presence or absence of $\mathrm{NaCl}$ treatment. The plants inoculated with $\mathrm{MA} 9$ showed an increase in their mineral content by 14.6 to $441 \%$, in salted and unsalted soils compared to negative controls (Table 5). The plants inoculated with MA17 (B. pumilus) showed 24 and $56 \%$ higher total mineral contents compared to those of the control plants under primary and secondary salinity, respectively. The total mineral content in MA14-treated plant was greater than those measured in MA9-treated one.

\section{Discussion}

Isolating PGPB from saline soil and their screening for PGPB traits in vitro on the aim to be used for durum wheat seed biopriming to promote its tolerance to salt stress. To our knowledge, the present study is the 
first on screening the diversity of of halotolerant diazotrophic PGPB from saline soil. The genus Bacillus is known for its ability to grow under various abiotic and biotic stresses. Thus, it is considered in numerous plant studies as the dominant isolate [30], and is therefore recognized as a strict aerobe or facultative anaerobe [31].

Soil application requires large amounts of inoculants which is economically demanding to the farming. Solid inoculants are easy to apply, while, liquid ones need careful handling during the transportation and after field inoculation. It was also reported that PGPB might release lytic enzymes and siderophores leading to pathogens growth restriction [32]. They also release certain antibiotics to support colonization [33]. In our work, we found that the strain MA17 was the most efficient in terms of bothplant growth promotion under stress conditions and head blight resistance induction. This was accompagnied by the production of diverse biologically active compounds by this strain including siderophores, lytic enzymes, growth hormones and a stable ACC deaminase activity. It is known that plant growth promoting rhizobacteria (PGPR) with 1aminocyclopropane-1-carboxylic acid $(A C C)$ deaminase activity has the potential to promote plant growth and development under adverse environmental conditions. Several approaches were described to promote plant growth under stressful conditions. Among which, the treatment of the seeds (priming) either by physical or chemical agents during storage or just before the sowing. Interestingly, appropriate conditions have been standardized for an efficient colonization of the seed by the bacterial inoculum during the seed priming process [34] to allow multiplication of PGPB in the seed as well as in the spermosphere even before sowing [35]. Thereafter, PGPB can invade the inner seed tissue, and trigger important biological activities in the seed. In this manner, germination might occurr rapidly and plant growth can be promoted [36]. In our study, we found that almost of the tested PGPB had different plant growth-promoting biological activities, of which MA17 is the only one that exhibited all of PGPB traits.

Moreover, most of the PGPB used offered a significant improvement of plant growth ability under salinity stress as demonstrated by based on the evaluation of numerous agro-morphological traits of the bioprimed wheat plants. Our results are in accordance with previous report describing the abiliy of different PGPB strains, like those belonging to the Bacillus genus, to provide in abiotic stress tolerance in various plant species including potato [24], radish [25] rice, mung bean and chickpea [26].

In addition, it was reported that associating bio-osmopriming with bacterial coating greatly improved uniformity of the germination and plant growth traits [37]. Also, combining Azotobacter chroococcum, with Azospirillum lipoferum and $80 \mathrm{~kg} \mathrm{ha}^{-1}$ urea and $60 \mathrm{~kg} \mathrm{ha}^{-1} \mathrm{P}_{2} \mathrm{O}_{5}$ as seed priming significantly improved the barley yield parameters such as grain weight, dry matter accumulation, biological yield, grain yield and harvest index [38].

Priming with Azotobacter and Azospirillum strains promoted the growth of wheat plants as revealed by the increase in total length of root, vegetative parts, dry mass of plants and grains, root surface and the quality in nitrogen, proteins and mineral matter. On the same trands, biopriming of safflower with Pseudomonas strain 186 increased grain number per head, heads per plant, the number of branches, , diameter of head, , grains per plant, grain yield of the plants and 1000 grain weight [39]. 
On the other hand, our results of biopriming in durum wheat revealed an increase in $\mathrm{N}$ and other essential elements wich are sufficiently transferred to plants by the tested diazotrophic PGPB strains. Clearly, such an increase of these elements in plant organs is related to $\mathrm{N}_{2}$ fixation and $\mathrm{P}$ solubilization capacity of the selected PGPB strains via their ability to solubilize insoluble phosphates, allowing plant uptake via several processes such as acidification, chelation, and ion-exchanger actions [40].

The promotion in plant growth and N/protein levels in bioprmed plants clearly reflects the ability of the bacterial isolates to offer a higher nutrient flux to the plant resulting in a higher plant biomass. In a related study, it was demonstrated that the N-content in wheat shoot increased by $1.7-2.43 \%$ following pretreatment with PGPB strains as compared to untreated control [41].

Morever, the increase in total mineral concentrations in plant tissues might be due to an efficient biochemical activity of the selected PGPB (MA17, and MA19). Additional impactful traits detected in our tested PGPB strains including the production of hydrolytic enzymes, ( $\beta$-glucanase, protease, amylase), EPS and ACC deaminase actitiy have been previously reported to stimulate plant growth under stress conditions in a direct manner However, it was reported that PGPB can indirectly improve plant growth under stress conditions through producing siderophores (iron chelating, fungal antagonist), antimicrobial compounds (microbial antagonist) and chitinase (fungal cell wall degrading enzyme), known for their role in protecting planst from pathogen intruders $[42,43]$.

\section{Conclusion}

Both in vitro and in vivo studies showed that MA9, MA14 MA9, MA14, MA17 and MA19 strains were able to play the PGPB role. Yet, biopriming with Bacillus strain MA17 offered the highest bioprotection against FHB, plant growth promotion, and salinity tolerance. Hence, the MA17 strain should further be evaluated under field condition and formulated for commercial production. Besides, the strain could further be evaluated for its potential role in bioprotection and growth promotion of other crop plants. We believe, the strain has a potential to significantly contribute to wheat production in the arid and semi-arid region, especially the salt affected Middle Eastern Region, besides its potential role in improving wheat production under biotic and abiotic stresses in other parts of the world.

\section{Methods}

\section{Isolation of diazotrophic bacteria}

For the selective isolation of diazotrophic bacteria, root samples were washed to eliminate soil traces and then successively washed by sterile deionized water. The macerate of clean roots was inoculated in a culture flask containing Burk's $\mathrm{N}$-free medium and incubated for 7 days under $30^{\circ} \mathrm{C}$ temperature. After that, $0.1 \mathrm{~mL}$ aliquots of a 6-fold serial dilution of this latest, and were spread in Petri plates in duplicate over the Burk's $\mathrm{N}$-free medium supplemented with yeast extract at $0.5 \%$. After an incubation for 7 days $\left(30^{\circ} \mathrm{C}\right)$, the different colonies obtained on the medium that appear to be morphologically different were isolated and subcultured for further analysis. 
To isolate the endophytic diazotroph bacteria in a selective manner, root samples have been successively washed and treated by a chlorinated solution for $2 \mathrm{mn}$, alcohol solution for $45 \mathrm{~s}$ and successively washed by sterile deionized water. .

Assessment of the nitrogen-fixation (diazotrophic) potential of the isolatesin a first step, the two mineral nitrogen free media: NFMM and NFb have been used to assess the nitrogen-fixation potential of our isolated bacteriafirst by testing their growth on. In a second step, the method of Quantification of $\mathrm{N}$ fixing capacity and the ARA test were used to investigate the nitrogenase activity of these isolates. The isolates that showed positive and predominant growth during the first 3 to 4 days were selected for quantification based on the acetylene reduction method in nitrogen-free semisolid NFb [44] and the Kjeldahl N digestion and distillation system. The selected isolates were incubated in $10 \mathrm{~mL}$ of NFb broth in a rotary agitator for 5 days at $150 \mathrm{rpm}$ and $28^{\circ} \mathrm{C}$. The $\mathrm{N}$ content in the microbial tissues was determined according to Kizilkaya [45].

\section{Exopolysaccharide production}

The production of exopolysaccharides was qualitatively determined as previously described by Paulo, Vasconcelos [46]. In fact, paper discs of 5-mm diameter were separately inoculated with the different bacterial strains, and placed in a medium containing yeast extract (2\%); $\mathrm{K}_{2} \mathrm{HPO}_{4}(1.5 \%) ; \mathrm{MgSO}_{4}(0.02 \%)$; $\mathrm{MnSO}_{4}(0.0015 \%) ; \mathrm{FeSO}_{4}(0.0015 \%) ; \mathrm{CaCl}_{2}(0.003 \%) ; \mathrm{NaCl}(0.0015 \%) ;$ agar (1.5\%) supplemented with saccharose $(10 \%, \mathrm{pH} 7.5)$. The halo production and its slime appearance indicated EPS production. Moreover, EPS production was confirmed by the formation of a precipitate when mixing a portion of the mucoid substance with $2 \mathrm{~mL}$ absolute ethanol.

\section{ACC deaminase activity assay}

The assessment of the ACC deaminase activity was carried out by dertemining the content of a-ketobutyric acid released after ACC cleavage as previously reported by Penrose and Glick [47]. In brief, the bacterial cells were grown in minimal medium containing ACC as the sole nitrogen source in a $15 \mathrm{~mL}$ TSB medium up to log phase to elicit their ACC deaminase activity . The production of a-ketobutyrate was monitored at 540 $\mathrm{nm}$ absorbance. A a standard curve of a-ketobutyrate ranging from 0.1 to $1.0 \mu \mathrm{mol}$ was used to calculate the ACC deaminase activity that was expressedas the amount of a-ketobutyrate generated per $\mathrm{mg}$ of protein per hour.

\section{Production of lytic enzymes}

B-glucanase, chitinase, protease and phytase activities were assessed by using B-glucan, chitin, milk and phytic acid as substrate in a modified LB agar medium containing: $1.0 \%$ Enzyme substrate, $1 \% \mathrm{NaCl}, 0.5 \%$ levure extract, $0.5 \%$ Peptone, $0.5 \%\left(\mathrm{NH}_{4}\right)_{2} \mathrm{HPO}_{4}, 0.02 \% \mathrm{KCl}, 0.3 \% \mathrm{MgSO}_{4} / 7 \mathrm{H}_{2} \mathrm{O}$. The isolates were spotted in plates, incubated for 3 days at $30^{\circ} \mathrm{C}$ and the halo diameter was observed.

\section{In Vitro plant growth promoting and biocontrol potential of bacterial isolates:}


The isolated bacteria were investigated for various plant growth promoting (PGP) as well as biocontrol activities. PGP parameters included HCN production [48], IAA production in the presence or absence of $0.5 \%$ tryptophan [49,50], siderophore production in agar plates using chromeazurol S (CAS) [51], phosphate solubilization on pikovskya's medium [52,53], and organic acid production on NFMM medium using bromophenol blue as $\mathrm{pH}$ indicator $[54,55]$.

\section{Biocontrol activity against wheat fungal attack in greenhouse}

To investigate the ability of the various bacterial strains to suppress head blight disease in wheat. In fact, wheat seeds were desinfected by immersion in $\mathrm{NaClO}(2 \%)$ for 3 min succeeded by an incubation in ethanol (75\%) for 2 min before to be rinsed 3 times in sterile distilled water.

On the other hand, our selected bacterial strains were grown in LB medium before to be harvested by centrifugation for $10 \mathrm{~min}$ at $5000 \mathrm{xg}$ and whashed twice with phosphate-buffered saline (PBS, pH 7.0) .

After being bioprimed in a $10^{8}$ bacterial suspension for $1 \mathrm{~h}$, seeds were placed on $9-\mathrm{cm}$ plates covered with sterile wet filter paper and incubated for $72 \mathrm{~h}$ at $25^{\circ} \mathrm{C}$ for germination. Thereafter, the obtained plantlets were placed in the soil in a growth chamber at $25^{\circ} \mathrm{C}$ under $16 / 8 \mathrm{~h}$ photoperiod and irrigated with a $1 / 2$ hoagland solution. One week later, wheat seedlings were inoculated by a $2 \mathrm{ml} F$. graminarum suspension $\left(10^{7} \mathrm{CFU} / \mathrm{ml}\right)$.

Pot experiment of biocontrol activity of two selected PGPB's for this experience: MA14 and MA17, against wheat pathogenic wilt, were preceded in controlled culture chamber under sterilized agricultural soil. The following treatments were applied: control 1: not bioprimed; control 2: only inoculated with F. graminarum; treatment1: seed bioprimed with MA14and inoculated with F. graminarum, treatment2: seed bioprimed with MA17and inoculated with F. graminarum. The percentage of disease incidence and severity were determined at 30 days after sowing. Each treatment had seven replicates. The control efficiency (CE) was determined according to the formula: CE (\%) $=($ DIcontrol2 - DIx)/DIcontrol $2 \times 100 \%$ (DI: disease index, $x$ : one of the treatments).

\section{Wheat inoculation assays}

Inoculum preparation and seed coating

Wheat seeds of "Aouija" variety provided by the Agriculture Research Station at the Centre of Biotechnology of Sfax. PGPB were incubated in LB broth overnight with constant shaking at $28 \pm 2{ }^{\circ} \mathrm{C}$. Cells were harvested by centrifugation before to be re-suspended in normal saline to reach an optimum growth $\left(O D=10^{8}\right.$ cells per $\mathrm{ml}$ at $\lambda=600)$. Seeds of Aouija were surface sterilized with $\mathrm{HgCl} 2(0.1 \%)$ for $2 \mathrm{~min}$ and rinced twice with sterile distilled water. After that, the bacterial suspension was added to seeds and subjected to a constant shaking along with a continuous supplementation of the sterile carrier materialtill a formation of a thin film is detectible. Finally, the coated seeds were dried before sowing.

\section{Pot trials}

Page 10/22 
Natural soil was used in this assay without sterilization. This soil was iso-humic (Ustifluvent) with $\mathrm{pH} 7.05$, EC $0.21 \mathrm{mS} \mathrm{m}^{-1}, 4.40 \mathrm{~g} \mathrm{kg-1}$ organic carbon, $89 \mathrm{~kg}$ ha-1 available $\mathrm{N}$ (alkaline permanganate extractable). After germination of the coated seeds (7 days), plantelts were placed in a glasshouse for five months in a completely randomized design. Trial 1: This experiment was conducted by seed without PGPB in small pots (9 cm diameter) containing natural soil salinized by $150 \mathrm{mM} \mathrm{NaClas} \mathrm{negative} \mathrm{control.} \mathrm{The} \mathrm{plants} \mathrm{grown}$ without PGPB and sand salinization were used as positive control. Trial 2: In this experiment, seed biopriming with PGPB in small pots containing natural soil (1 Kg/pot) salinized by $150 \mathrm{mM}$ without any bacterial treatment.

Trial 3: The experiment was conducted by seed biopriming with PGPB in small pots containing natural sand $(1 \mathrm{Kg} / \mathrm{pot})$.

\section{Statistical Analysis}

The data obtained from biochemical characterization, seed germination and plant growth parameters were subjected to the Duncan's Multiple Range Test (DMRT) using the Statistica software (ver. 10.1). For seed biopriming, wheat growth test, and for antagonism test the data were analyzed by the Duncan's Multiple Range Test (DMRT) using the IBM SPPSS software (ver. 21.1, SPSS Inc. www.spss.com). The significance level for all analyses was $P=0.05$.

\section{Declarations}

\section{Funding}

This work is done under government funding from the ministry of higher education and scientific research in Tunisia.

\section{Availability of data and materials}

All data generated or analyzed during this study are included in this published article and in supplementary materials.

\section{Ethics approval and consent to participate}

Not applicable.

\section{Consent for publication}

Not applicable.

\section{Competing interests}

The authors declare that they have no competing interests.

\section{Authors' contributions}


Experimental design and write up by $A H B, M J, L D, A A, M B A, H H, M B A \&$ NAF. MBA, AA and HH carried out the statistical analysis. NAF final editing \& correspondence. All authors approved the final version.

\section{Acknowledgements}

We are very grateful to the two teams from the Legumes and Bioactive Substances laboratories at the Biotechnology Center of Borj-Cedria Ben-Arous, Tunisia for their collaboration, especially the two head of laboratories Prof. LIMAM Ferid and Prof. MHAMDI Ridha. We also dully acknowledge South African Biodesign Initiative-Technology Innovation Agency grant number 420/01 SABDI 16/1021 for covering 'Open Access' publication cost.

\section{Tables}

Table 1: Plant growth-promoting and other properties of selected isolates from coastal saline soil in Tunisia.
Hydrolytic enzyme properties
PGP properties
Antifungal activity

\begin{tabular}{|c|c|c|c|c|c|c|c|c|c|c|}
\hline \multirow{2}{*}{\multicolumn{2}{|c|}{$\begin{array}{l}\text { PGPB } \\
\text { strain B- } \\
\end{array}$}} & \multirow[t]{2}{*}{ Protease } & \multirow[t]{2}{*}{ Chitinase } & \multirow[t]{2}{*}{ Siderophore } & \multirow[t]{2}{*}{$\begin{array}{c}\text { ACC } \\
\text { deaminase* }\end{array}$} & \multirow[t]{2}{*}{ EPS } & \multirow[t]{2}{*}{$\begin{array}{c}\text { Rhizoctonia } \\
\text { solani }\end{array}$} & \multirow[t]{2}{*}{$\begin{array}{l}\text { Fusarium } \\
\text { solani }\end{array}$} & \multirow{2}{*}{$\begin{array}{l}\text { Fusarium } \\
\text { oxysporum }\end{array}$} & \multirow{2}{*}{$\begin{array}{l}\text { Fusarium } \\
\text { graminarum }\end{array}$} \\
\hline & & & & & & & & & & \\
\hline MA9 & ++ & +++ & + & + & +++ & ++++ & +++ & + & - & + \\
\hline MA14 & +++ & ++++ & ++ & ++++ & ++ & + & - & - & - & - \\
\hline MA17 & +++ & ++++ & +++ & ++ & + & ++++ & +++ & +++ & ++ & +++ \\
\hline MA19 & +++ & +++ & ++++ & +++ & +++ & + & +++ & + & - & +++ \\
\hline
\end{tabular}

*ACC deaminase activity was measured after 7 days of bacterial growth. Data showing only four identified isolates, all experiments were done in duplicate. (-) absence of activity, (+) low, (++) medium, (+++) high, very high $(++++)$.

Table 2: Plant growth promoting attributes of salt tolerant rhizobacteria at $2 \% \mathrm{NaCl}$ concentration. 


\begin{tabular}{|c|c|c|c|c|c|}
\hline Strain & $\begin{array}{l}\text { Pellicle } \\
\text { formation }\end{array}$ & $\begin{array}{l}\text { N-free growth } \\
\text { medium }\end{array}$ & $\begin{array}{l}\text { Blue bromothymol color } \\
\text { change }\end{array}$ & $\begin{array}{l}\text { Dinitrogen } \\
\text { fixation (mg N2 } \\
\text { fixed } 50 \mathrm{ml}^{-1} \\
\text { culture media } \\
72 \mathrm{~h}^{-1} \text { ) }\end{array}$ & $\begin{array}{l}\begin{array}{l}\text { ARA(nmol } \\
\text { of }\end{array} \\
\text { C2H4 } \\
\text { formed } \\
\mathrm{ml}^{-1} \text { culture } \\
\text { media } 72 \\
\left.\mathrm{~h}^{-1}\right)\end{array}$ \\
\hline MA9 & + & ++ & Green blue & $24.548 \mathrm{~b}$ & $2.348 \mathrm{~b}$ \\
\hline MA14 & ++ & +++ & Yellow & $09.458 \mathrm{~b}$ & $0.452 a$ \\
\hline MA17 & ++ & ++ & Blue & $51.023 \mathrm{~b}$ & $3.125 b$ \\
\hline MA19 & + & +++ & Yellow & $37.149 \mathrm{~b}$ & $2.428 \mathrm{~b}$ \\
\hline MTCC2460* & + & ++ & Blue & $5.03 a$ & $1.64 \mathrm{a}$ \\
\hline
\end{tabular}

Data showing only of four identified isolates, all biochemical analysis are in triplicate. Means in the columns followed by same superscript letters indicate no significant difference $(P=0.05)$ by Duncan's Multiple Range Test (DMRT). * Azotobacter vinelandii.

Table 3: Bioprotection efficiency of PGPB strains against wheat fungal wilt caused by Fusarium graminarum.

\begin{tabular}{lll}
\hline Treatment & Disease index (\%) Bioprotection efficiency (\%) \\
\hline Control-1 & $0 \pm 0$ & - \\
Control-2 & $89.58 \pm 0.38 \mathrm{a}$ & - \\
\hline Treatment-1 $76 \pm 0.18 \mathrm{~b}$ & 24.5 \\
\hline Treatment-2 $36 \pm 0.89 \mathrm{c}$ & 64.5 \\
\hline
\end{tabular}

Control1 (not inoculated with any microbe), Control-2 (only inoculated with F.graminarum), Treatment1 (inoculated with MA14 and F.graminarum) and Treatment-2 (inoculated with MA17 and F.graminarum). Values with the different letter within the same column are significantly different at $\mathrm{P}<0.05$ according to Duncan Multiple Range Test (DMRT). Numbers followed by the " \pm " are standard errors. 
Table 4: Influence of seed biopriming by PGPB on growth parameters (root and shoot length) of wheat plants, under non-saline (control) and saline (in planta) conditions.

$\overline{\text { Bacterized seed with } \mathrm{NaCl} \text { mol. } \mathrm{l}^{-1} \text { Root length (cm) \%Increase Shoot length (cm) \%Increase }}$

\begin{tabular}{cccccc}
\hline Control* & 0.025 & $5 \mathrm{ab}$ & - & $42.57 \mathrm{ab}$ & - \\
MA9 & 0.025 & $7 \mathrm{~cd}$ & 40 & $38.57 \mathrm{ab}$ & 0 \\
MA14 & 0.025 & $16.2 \mathrm{e}$ & 131.42 & $61 \mathrm{bc}$ & 14.33 \\
MA17 & 0.025 & $8.5 \mathrm{~d}$ & 70 & $63.64 \mathrm{~d}$ & 49.49 \\
MA19 & 0.025 & $5 \mathrm{ab}$ & 0 & $63.14 \mathrm{~cd}$ & 48.32 \\
Control* & 0.125 & $3.7 \mathrm{a}$ & - & $37.87 \mathrm{a}$ & - \\
MA9 & 0.125 & $5.5 \mathrm{abc}$ & 48.64 & $43.45 \mathrm{bc}$ & 14.73 \\
MA14 & 0.125 & $20.2 \mathrm{f}$ & 459.46 & $35.14 \mathrm{a}$ & 0 \\
MA17 & 0.125 & $4.7 \mathrm{ab}$ & 27 & $75.34 \mathrm{~d}$ & 99.2 \\
MA19 & 0.125 & $6.3 \mathrm{bcd}$ & 70.27 & $52.72 \mathrm{bc}$ & 39.21 \\
\hline
\end{tabular}

* Seed without bacterial treatment.

Table 5: Influence of seed biopriming by PGPB on growth parameters (total dry weight and 100 grain weight) of wheat plants, under non-saline (control) and saline (in planta) conditions. 


\begin{tabular}{|c|c|c|c|c|c|}
\hline $\begin{array}{l}\text { Bacterized seed } \\
\text { with }\end{array}$ & $\begin{array}{c}\mathrm{NaCl} \\
\mathrm{mol.}^{-1}\end{array}$ & $\begin{array}{c}\text { Total Dry Weight } \\
\text { (g/plant) }\end{array}$ & $\begin{array}{c}\text { Dry Mass Increase } \\
\text { (\%) }\end{array}$ & $\begin{array}{c}\text { Grain Weight } \\
(\mathrm{g})^{*}\end{array}$ & $\begin{array}{c}\text { Grain Weight Increase } \\
(\%)\end{array}$ \\
\hline Control** & 0.025 & $1.68 \mathrm{a}$ & - & $4.182 \mathrm{~b}$ & - \\
\hline MA9 & 0.025 & $2.55 \mathrm{~b}$ & 51.78 & $4.181 \mathrm{~b}$ & 0 \\
\hline MA14 & 0.025 & $3.09 \mathrm{~b}$ & 83.92 & $4.48 \mathrm{~cd}$ & 07.17 \\
\hline$\underline{\text { MA17 }}$ & 0.025 & $\underline{5.04 b}$ & $\underline{200}$ & $\underline{5.44 e}$ & $\underline{30.14}$ \\
\hline MA19 & 0.025 & $3.61 \mathrm{~b}$ & 114.88 & $4.67 \mathrm{~d}$ & 11.72 \\
\hline Control** & 0.125 & $1.01 \mathrm{a}$ & - & $3.38 \mathrm{a}$ & - \\
\hline MA9 & 0.125 & $2.48 \mathrm{~b}$ & 145.54 & $4.16 \mathrm{~b}$ & 23 \\
\hline MA14 & 0.125 & $2.65 b$ & 162.37 & $4.31 \mathrm{bc}$ & 27.51 \\
\hline$\underline{\text { MA17 }}$ & 0.125 & $\underline{7.45 \mathrm{~b}}$ & $\underline{637.62}$ & $\underline{6 f}$ & $\underline{77.51}$ \\
\hline MA19 & 0.125 & $2.69 \mathrm{~b}$ & 166.33 & $4.55 \mathrm{~d}$ & 34.61 \\
\hline
\end{tabular}

*Weight of 100 grains

**Seed without bacterial strain

References 
1. Allakhverdiev, S.I., et al., Inactivation of photosystems I and II in response to osmotic stress in Synechococcus. Contribution of water channels. Plant Physiology, 2000. 122(4): p. 1201-1208.

2. Wang, W., B. Vinocur, and A. Altman, Plant responses to drought, salinity and extreme temperatures: towards genetic engineering for stress tolerance. Planta, 2003. 218(1): p. 1-14.

3. Dimkpa, C., T. Weinand, and F. Asch, Plant-rhizobacteria interactions alleviate abiotic stress conditions. Plant, Cell \& Environment, 2009. 32(12): p. 1682-1694.

4. Vessey, J.K., Plant growth promoting rhizobacteria as biofertilizers. Plant and soil, 2003. 255(2): p. $571-586$.

5. Rojas-Tapias, D., et al., Effect of inoculation with plant growth-promoting bacteria (PGPB) on amelioration of saline stress in maize (Zea mays). Applied Soil Ecology, 2012. 61: p. 264-272.

6. Silveira, F.A., et al., Ecology and evolution of plant diversity in the endangered campo rupestre: a neglected conservation priority. Plant and soil, 2016. 403(1-2): p. 129-152.

7. Paparella, S., et al., Seed priming: state of the art and new perspectives. Plant Cell Reports, 2015. 34(8): p. 1281-1293.

8. Jisha, K., K. Vijayakumari, and J.T. Puthur, Seed priming for abiotic stress tolerance: an overview. Acta Physiologiae Plantarum, 2013. 35(5): p. 1381-1396.

9. Ashraf, M. and M.R. Foolad, Pre-sowing seed treatment-A shotgun approach to improve germination, plant growth, and crop yield under saline and non-saline conditions. Advances in agronomy, 2005. 88: p. 223-271.

10. Sivritepe, H.Ö., et al., The effects of $\mathrm{NaCl}$ pre-treatments on salt tolerance of melons grown under long-term salinity. Scientia Horticulturae, 2005. 106(4): p. 568-581.

11. Gholami, M., F. Mokhtarian, and B. Baninasab, Seed halopriming improves the germination performance of black seed (Nigella sativa) under salinity stress conditions. Journal of Crop Science and Biotechnology, 2015. 18(1): p. 21-26.

12. Maiti, R. and K. Pramanik, Vegetable Seed Priming: a Low Cost, Simple and Powerful Techniques for Farmers' Livelihood. International Journal of Bio-Resource \& Stress Management, 2013. 4(4).

13. Khan, H., et al., Hormonal priming alleviates salt stress in hot pepper (Capsicum annuum L.). Soil Environ, 2009. 28(2): p. 130-135.

14. Khan, $\mathrm{H}$., et al., Effect of seed priming with $\mathrm{NaCl}$ on salinity tolerance of hot pepper (Capsicum annuum L.) at seedling stage. Soil Environ, 2009. 28(1): p. 81-87.

15. Nasri, N., et al., The effect of osmopriming on germination, seedling growth and phosphatase activities of lettuce under saline condition. African Journal of Biotechnology, 2011. 10(65): p. 1436614372.

16. Tabatabaei, S., The effect of priming on germination indexes and seed reserve utilization of maize seeds under salinity stress. 2014.

17. Dkhil, B.B., A. Issa, and M. Denden, Germination and seedling emergence of primed okra (Abelmoschus esculentus L.) seeds under salt stress and low temperature. American Journal of Plant Physiology, 2014. 9(2): p. 38-45.

18. Pradhan, N., et al., Osmopriming of tomato genotypes with polyethylene glycol 6000 induces tolerance to salinity stress. Trends in Biosciences, 2014. 7: p. 4412-4417.

19. Naz, F., et al., Effect of $\mathrm{NaCl}$ stress on Pisum sativum germination and seedling growth with the influence of seed priming with potassium $(\mathrm{KCL}$ and $\mathrm{KOH})$. American-Eurasian Journal of Agricultural and Environmental Sciences, 2014. 14(11): p. 1304-1311. 
20. Aloui, H., et al., Germination and growth in control and primed seeds of pepper as affected by salt stress. Cercetari agronomice în Moldova, 2014. 47(3): p. 83-95.

21. Zavariyan, A.M., M.Y. Rad, and M. Asghari, Effect of seed priming by potassium nitrate on germination and biochemical indices in Silybum marianum L. under salinity stress. International Journal of Life Sciences, 2015. 9(1): p. 23-29.

22. Miladinov, Z.J., et al., Optimal time of soybean seed priming and primer effect under salt stress conditions. Journal of Agricultural Sciences, 2015. 60(2): p. 109-117.

23. Anitha, D., et al., Microbial endophytes and their potential for improved bioremediation and biotransformation: a review. Indo Am J Pharmaceutical Res, 2013. 3: p. 6408-17.

24. Gururani, M.A., et al., Plant growth-promoting rhizobacteria enhance abiotic stress tolerance in Solanum tuberosum through inducing changes in the expression of ROS-scavenging enzymes and improved photosynthetic performance. Journal of Plant Growth Regulation, 2013. 32(2): p. 245-258.

25. Kaymak, H.Ç., et al., The effects of bio-priming with PGPR on germination of radish (Raphanus sativus L.) seeds under saline conditions. Turkish Journal of Agriculture and Forestry, 2009. 33(2): p. 173-179.

26. Chakraborty, U., et al., Plant growth promotion and amelioration of salinity stress in crop plants by a salt-tolerant bacterium. Recent Research in Science and Technology, 2011. 3(11).

27. Khalid, A., M. Arshad, and Z. Zahir, Screening plant growth-promoting rhizobacteria for improving growth and yield of wheat. Journal of Applied Microbiology, 2004. 96(3): p. 473-480.

28. Cheng, Z., E. Park, and B.R. Glick, 1-Aminocyclopropane-1-carboxylate deaminase from Pseudomonas putida UW4 facilitates the growth of canola in the presence of salt. Canadian Journal of Microbiology, 2007. 53(7): p. 912-918.

29. Siddikee, M.A., et al., Enhancement of growth and salt tolerance of red pepper seedlings (Capsicum annuum L.) by regulating stress ethylene synthesis with halotolerant bacteria containing 1aminocyclopropane-1-carboxylic acid deaminase activity. Plant Physiology and Biochemistry, 2011. 49(4): p. 427-434.

30. Hallmann, J. and G. Berg, Spectrum and population dynamics of bacterial root endophytes, in Microbial root endophytes. 2006, Springer. p. 15-31.

31. Logan, N.A. and G. Halket, Developments in the taxonomy of aerobic, endospore-forming bacteria, in Endospore-forming Soil Bacteria. 2011, Springer. p. 1-29.

32. Compant, S., C. Clément, and A. Sessitsch, Plant growth-promoting bacteria in the rhizo-and endosphere of plants: their role, colonization, mechanisms involved and prospects for utilization. Soil Biology and Biochemistry, 2010. 42(5): p. 669-678.

33. Van Loon, L. and P. Bakker, Induced systemic resistance as a mechanism of disease suppression by rhizobacteria, in PGPR: Biocontrol and biofertilization. 2005, Springer. p. 39-66.

34. Burges, H.D., Formulation of microbial biopesticides: beneficial microorganisms, nematodes and seed treatments. 2012: Springer Science \& Business Media.

35. Taylor, A. and G. Harman, Concepts and technologies of selected seed treatments. Annual review of phytopathology, 1990. 28(1): p. 321-339.

36. Moeinzadeh, A., et al., Biopriming of Sunflower ('Helianthus annuus' L.) Seed with'Pseudomonas fluorescens' for Improvement of Seed Invigoration and Seedling Growth. Australian Journal of Crop Science, 2010. 4(7): p. 564.

37. Bennett, M.A., The use of biologicals to enhance vegetable seed quality. Seed Technology, 1998: p. 198-208. 
38. Mirshekari, B., et al., Effect of seed biopriming with plant growth promoting rhizobacteria (PGPR) on yield and dry matter accumulation of spring barley (Hordeum vulgare L.) at various levels of nitrogen and phosphorus fertilizers. Journal of Food, Agriculture \& Environment, 2012. 10(3/4): p. 314-320.

39. Sharifi, R., Study of nitrogen rates effects and seed biopriming with PGPR on quantitative and qualitative yield of safflower (Carthamus tinctorius L.). Technical Journal of Engineering and Applied Sciences, 2012. 2(7): p. 162-166.

40. Chao, W.-L. and M. Alexander, Mineral soils as carriers for Rhizobium inoculants. Appl. Environ. Microbiol., 1984. 47(1): p. 94-97.

41. Abbasi, M., et al., Isolation of plant growth promoting rhizobacteria from wheat rhizosphere and their effect on improving growth, yield and nutrient uptake of plants. Plant Biosystems, 2011. 145(1): $p$. 159-168.

42. Nagarajkumar, M., R. Bhaskaran, and R. Velazhahan, Involvement of secondary metabolites and extracellular lytic enzymes produced by Pseudomonas fluorescens in inhibition of Rhizoctonia solani, the rice sheath blight pathogen. Microbiological Research, 2004. 159(1): p. 73-81.

43. Zhou, T., M.A. Geller, and W. Lin, An observational study on the latitudes where wave forcing drives Brewer-Dobson upwelling. Journal of the Atmospheric Sciences, 2012. 69(6): p. 1916-1935.

44. Eckert, B., et al., Azospirillum doebereinerae sp. nov., a nitrogen-fixing bacterium associated with the C4-grass Miscanthus. International Journal of Systematic and Evolutionary Microbiology, 2001. 51(1): p. 17-26.

45. Kizilkaya, R., Nitrogen fixation capacity of Azotobacter spp. strains isolated from soils in different ecosystems and relationship between them and the microbiological properties of soils. J. Environ. Biol, 2009. 30(1): p. 73-82.

46. Paulo, E.M., et al., An alternative method for screening lactic acid bacteria for the production of exopolysaccharides with rapid confirmation. Food Science and Technology, 2012. 32(4): p. 710-714.

47. Penrose, D.M. and B.R. Glick, Methods for isolating and characterizing ACC deaminasecontaining plant growth-promoting rhizobacteria. Physiologia plantarum, 2003. 118(1): p. 10-15.

48. Bakker, A.W. and B. Schippers, Microbial cyanide production in the rhizosphere in relation to potato yield reduction and Pseudomonas spp-mediated plant growth-stimulation. Soil Biology and Biochemistry, 1987. 19(4): p. 451-457.

49. Patten, C.L. and B.R. Glick, Role of Pseudomonas putida indoleacetic acid in development of the host plant root system. Appl. Environ. Microbiol., 2002. 68(8): p. 3795-3801.

50. Glickmann, E. and Y. Dessaux, A critical examination of the specificity of the salkowski reagent for indolic compounds produced by phytopathogenic bacteria. Appl. Environ. Microbiol., 1995. 61(2): p. 793-796.

51. Schwyn, B. and J. Neilands, Universal chemical assay for the detection and determination of siderophores. Analytical biochemistry, 1987. 160(1): p. 47-56.

52. Nautiyal, C.S., An efficient microbiological growth medium for screening phosphate solubilizing microorganisms. FEMS microbiology Letters, 1999. 170(1): p. 265-270.

53. SILVA, F.C.D.S., Manual de análises químicas de solos, plantas e fertilizantes. Vol. 627. 2009: Embrapa Informação Tecnológica; Rio de Janeiro: Embrapa Solos Brasília.

54. Dobereiner, J., I. Marriel, and M. Nery, Ecological distribution of Spirillum lipoferum Beijerinck. Canadian Journal of Microbiology, 1976. 22(10): p. 1464-1473.

55. Tarrand, J.J., N.R. Krieg, and J. Döbereiner, A taxonomic study of the Spirillum lipoferum group, with descriptions of a new genus, Azospirillum gen. nov. and two species, Azospirillum lipoferum 
(Beijerinck) comb. nov. and Azospirillum brasilense sp. nov. Canadian journal of microbiology, 1978. 24(8): p. 967-980.

\section{Figures}

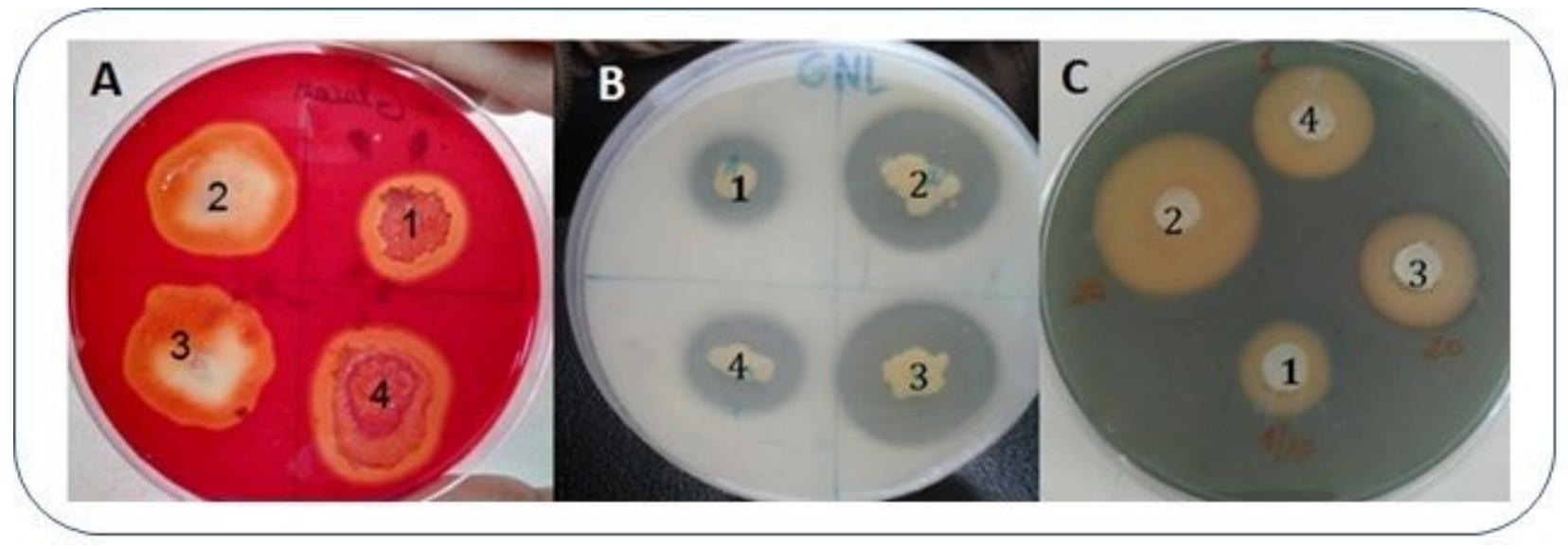

Figure 1

Production of $\beta$-Glucanase (A), proteases (B) and siderophores $(C)$ in vitro by bacterial isolate: 1: MA9, 2: MA14, 3: MA17 and 4: MA19 after 7days of growth at28 $\pm 2 \circ \mathrm{C}$. The formation of halo zone around the colonies shows the positive activity.

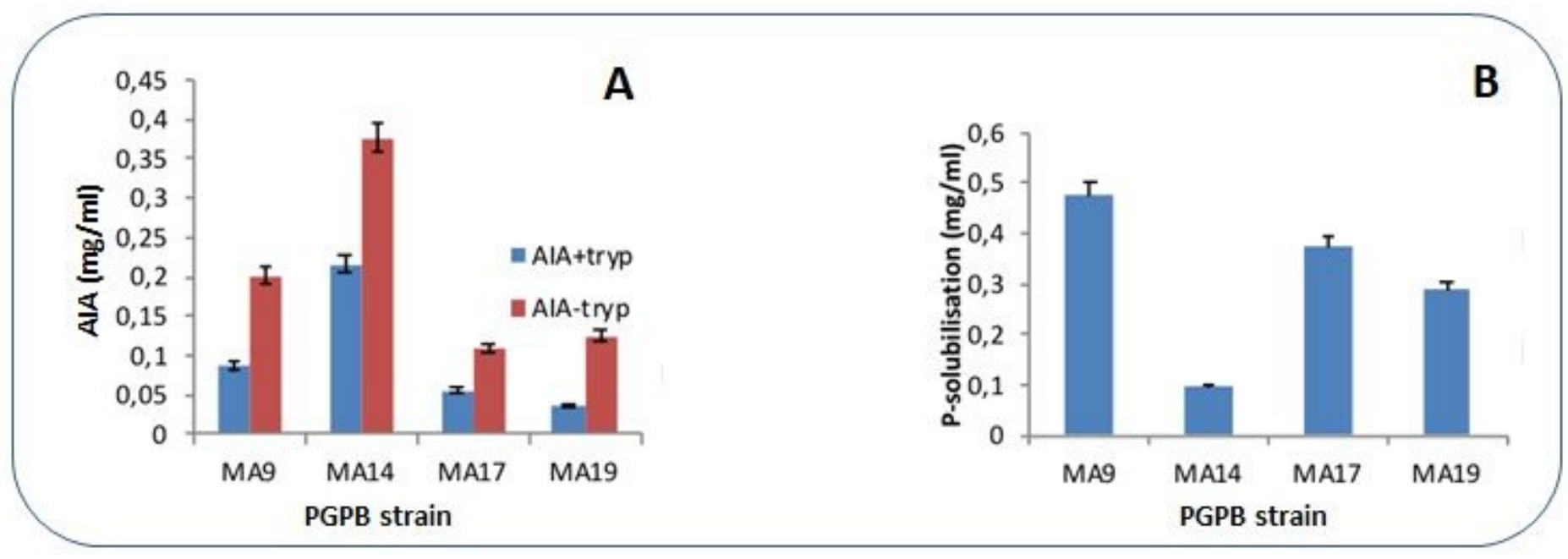

Figure 2

(A) AIA production, (B) P- solubilization of selected strains on $2 \% \mathrm{NaCl}$. Error bars show the standard deviation of the mean values of three replicates $(P<0.05)$. 


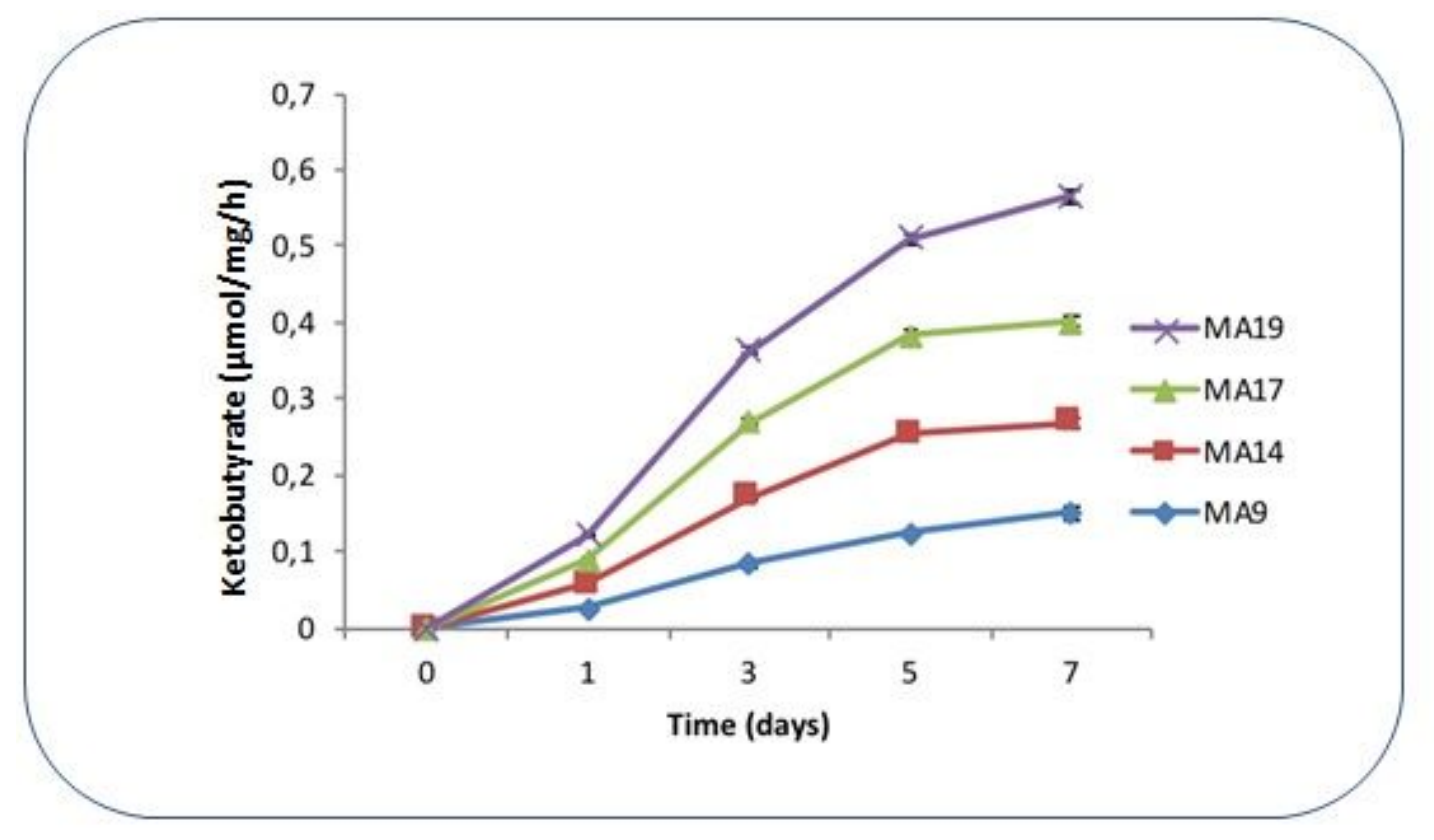

Figure 3

ACC deaminase activity expressed in $\mu$ mol ketobutyrate mg -1 h-1 (A) of selected bacteria on $\mathrm{N}$ free medium (NFMM) added by ACC (1-aminocyclopropane -1- carboxylate) as nitrogen source. Error bars show the standard deviation of the mean values of three replicates $(P<0.05)$.

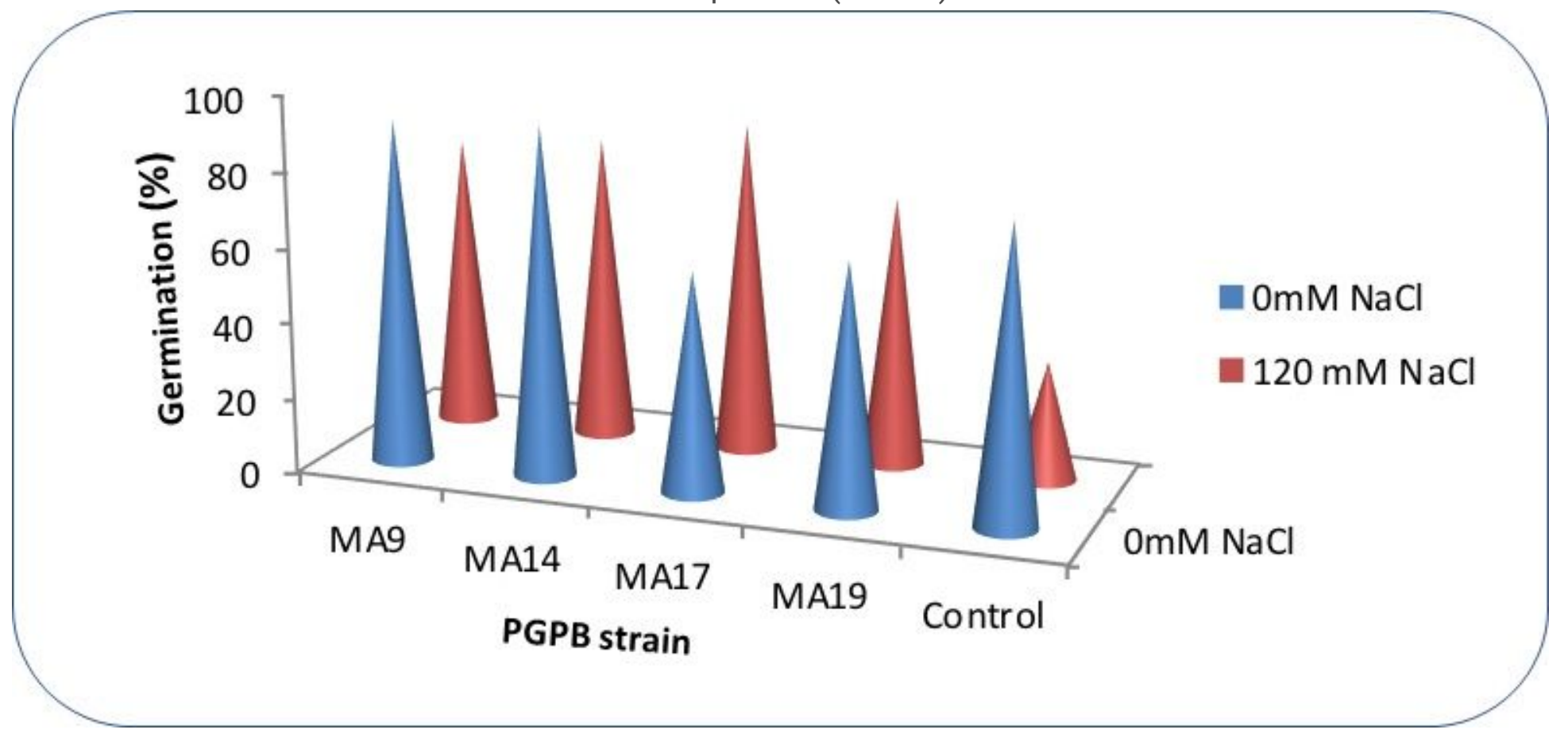

Figure 4

Effect of seed bio-priming by PGPB of germination of durum wheat under salt stress and natural conditions. The seed of wheat were incubated in a suspension of 108 bacteria on 0 and $150 \mathrm{mM} \mathrm{NaCl}$ at room temperature for $30 \mathrm{mn}$. Error bars show the standard deviation of the mean values of three replicates $(P<0.05)$. 


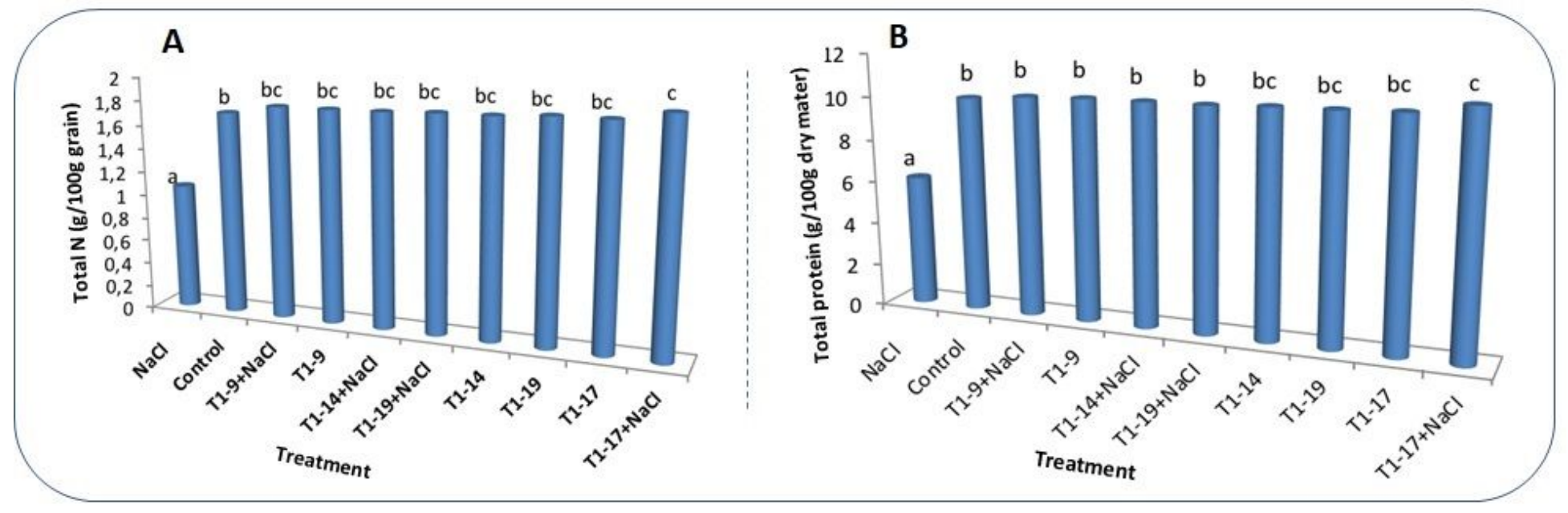

Figure 5

Effect of seed biopriming with PGPB's strains on the wheat N content ( $\mathrm{g} / 100 \mathrm{~g}$ wheat) (A) and the total protein content $(\mathrm{g} / 100 \mathrm{~g}$ wheat) $(B)$ of durum wheat plants under different salinity regime. Bars represent standard error of mean (SEM). Different letters above the error bars indicate significant difference at $P B$ 0.05. Control $=$ no bacterial inoculation under normal conditions; $\mathrm{NaCl}=$ no bacterial inoculation under salinized soil; $\mathrm{T} 1$ = biopriming seed; 9 = Bacillus pumilus; 14 = Virgibacillus sp.; 17 = Bacillus pumilus: $19=$ Bacillus tequilensis.

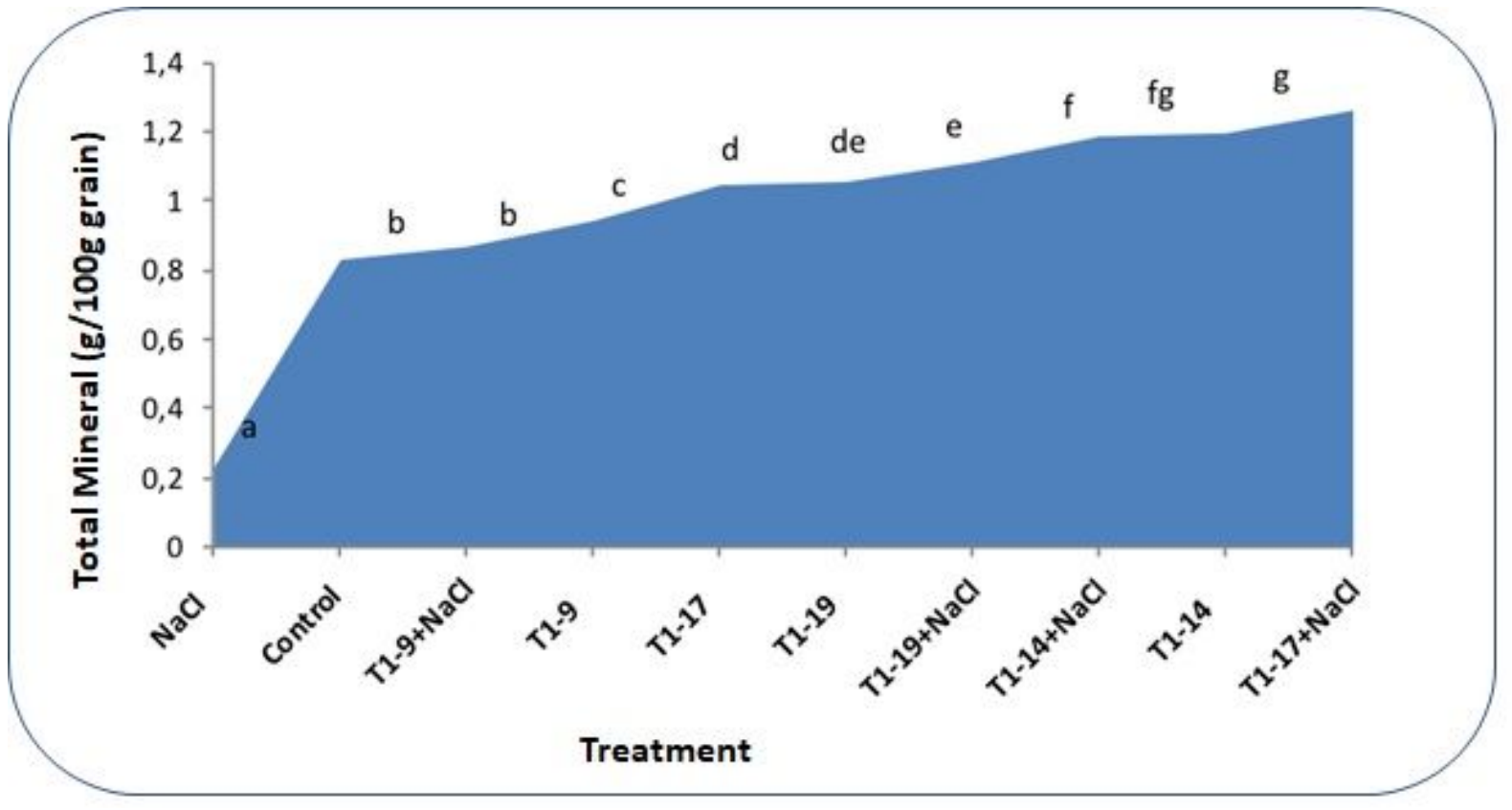

Figure 6

Effect of seed biopriming with PGPB's strains on the total mineral content ( $\mathrm{g} / 100 \mathrm{~g}$ wheat) of durum wheat plants under different salinity regime. Bars represent standard error of mean (SEM). Different letters above the error bars indicate significant difference at P B 0.05. Control = no bacterial inoculation under normal conditions; $\mathrm{NaCl}=$ no bacterial inoculation under salinized soil; $\mathrm{T} 1$ = biopriming seed; 9 = Bacillus pumilus; 14 = Virgibacillus sp.; 17 = Bacillus pumilus: 19 = Bacillus tequilensis . 


\section{Supplementary Files}

This is a list of supplementary files associated with this preprint. Click to download.

- SupplementaryData.docx 